HSV

\title{
National survey of diagnostic services for genital herpes
}

\section{A M Geretti, D W Brown}

Sex Transm Infect 2005;81:316-317. doi: 10.1136/sti.2004.013110

See end of article for authors' affiliations

.....................

Correspondence to: Dr Anna Maria Geretti, Department of Virology, Royal Free Hospital Pond Street, London NW3 2QG UK; a.geretti@medsch.ucl. ac.uk

Accepted for publication 28 October 2004

Objective: To investigate the provision of diagnostic services for genital herpes simplex virus (HSV) infection in the United Kingdom.

Methods: National survey of laboratories providing diagnostic services for genital herpes.

Results: Completed questionnaires were returned from 25/32 (78\%) laboratories participating in the Clinical Virology Network, including seven in London, 12 in the rest of England, one in Wales, four in Scotland, and one in Northern Ireland. Virus culture was the diagnostic method of choice in $20 / 25(80 \%)$ laboratories; 5/25 (20\%) routinely used HSV DNA detection by polymerase chain reaction (PCR). HSV PCR for DNA detection in cerebrospinal fluid (CSF) was available in 17/25 (68\%) laboratories. Typing of isolates (HSV-1 or HSV-2) was performed routinely in 22/25 (88\%) laboratories. Only 2/25 (8\%) laboratories offered HSV type specific serology, although an additional 12/25 (48\%) referred requests elsewhere. Consistent with this finding, the number of HSV type specific antibody tests referred to the Health Protection Agency increased by nearly fivefold between 1997 and 2003.

Conclusions: Virus culture remains the preferred diagnostic method for genital herpes, despite evidence indicating that its sensitivity is suboptimal compared to PCR. As HSV PCR is widely available for testing of CSF, it is recommended that clinicians and virologists discuss ways to implement PCR testing of genital swabs, thus enabling greater diagnostic accuracy. A call is made for studies to assess the use of HSV type specific serology in genitourinary medicine (GUM) settings, now that rapid and validated assays have become available and guidelines have been issues to provide recommendations on their use.

$\mathrm{n}$ n 1997, a survey of GUM consultants demonstrated that virus isolation from genital swabs was the most common diagnostic method for genital herpes in the United Kingdom and that information on typing of herpes simplex virus (HSV) isolates as HSV-1 or HSV-2 was available to $75 \%$ of respondents. ${ }^{1}$ There was limited availability of HSV type specific antibody tests. However, it was anticipated that type specific serology would contribute to clinical management once tests showing good performance became available. Since 1997, polymerase chain reaction (PCR) has been shown to increase HSV detection rates in genital swabs by $11-71 \%$ compared to virus isolation in cell culture. ${ }^{23}$ In addition, both commercial assays and well validated in-house assays ${ }^{4}$ with high specificity and sensitivity have been developed for the rapid detection of HSV type specific antibodies. The aim of this study was to assess the current provision of diagnostic assays for genital herpes in the light of these important diagnostic advances.

\section{METHODS}

In June 2003 a questionnaire was distributed via the UK Clinical Virology Network to 20 specialist virology centres and 12 specialist virology units. The questionnaire inquired about the routine diagnostic method employed for genital swabs; typing into HSV-1 and HSV-2; availability of HSV PCR for testing of cerebrospinal fluid (CSF) or other specimens; number of mucocutaneous swabs processed per year; availability of HSV type specific antibody assays; and trends in requests for HSV type specific serology over the previous 12 months. Where further clarification was required, the questionnaire was followed by a telephone interview of the respondents.

Completed questionnaires were returned by $25 / 32$ (78\%) laboratories, comprising seven in London, 12 in the rest of

Abbreviations: CSF, cerebrospinal fluid; GUM, genitourinary medicine; HSV, herpes simplex virus; PCR, polymerase chain reaction

England, one in Wales, four in Scotland, and one in Northern Ireland; together they processed over 60000 mucocutaneous swabs per year.

\section{Virus detection}

The routine diagnostic method was virus culture in 20/25 $(80 \%)$ laboratories and PCR in 5/25 (20\%). Of the laboratories using virus culture, $12 / 20(60 \%)$ provided HSV PCR for CSF samples. Each of the five laboratories using PCR for genital swabs reported processing over 1000 (1056 to 1869) mucocutaneous specimens per year. Two of the five laboratories employed standard gel based PCR and three employed real time PCR assays. All PCR assays followed inhouse protocols adapted from published methods. HSV typing into HSV-l and HSV-2 was provided by $22 / 25$ (88\%) laboratories, including 18/20 (90\%) laboratories using virus culture and $4 / 5(80 \%)$ laboratories using PCR.

\section{HSV type specific serology}

HSV type specific serology was provided by two laboratories using commercially available enzyme immunoassay and immunoblot kits. There was reluctance to adopt the new commercial assays because of low demand and lack of

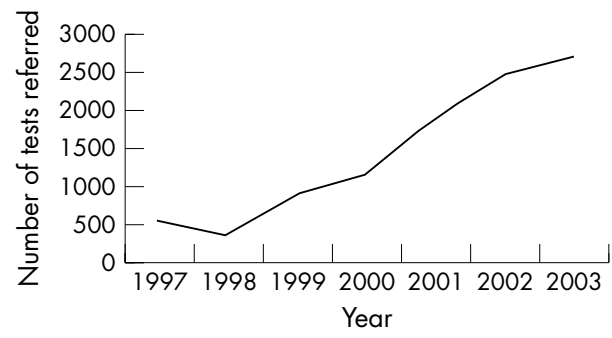

Figure 1 Trends in HSV type specific serology test requests referred to the Health Protection Agency between 1997 and 2003. 
familiarity with the assay performance and result interpretation. Twelve laboratories (48\%) referred requests elsewhere, predominantly to the Specialist and Reference Microbiology Division of the Health Protection Agency (previously Central Public Health Laboratory), where both an in-house and commercial assays were employed. Overall, access to HSV type specific serology was provided by 14/25 (56\%) laboratories, of which $6 / 14$ (43\%) reported that requests had been increasing in the previous 12 months. These trends were reflected in the number of requests for HSV type specific serology referred to the Health Protection Agency, which showed a nearly fivefold increase between 1997 and 2003 (fig 1).

\section{DISCUSSION}

This survey was designed to investigate current diagnostic tests for HSV in laboratories that participate in the Clinical Virology Network. The primary aim of the network is to facilitate the provision of a modern and comprehensive virology service across the United Kingdom and the establishment of best laboratory practice. Results showed that virus culture remains the most common diagnostic method for genital herpes, thus confirming the findings of the survey conducted in 1997. ${ }^{1}$ Over the last 8 years, there have been at least 14 large studies comparing virus culture with PCR for HSV detection in mucocutaneous swabs, together comprising data from over 3500 patients. $^{235-9}$ Without exception, these studies demonstrated that the sensitivity of virus culture was suboptimal compared to PCR, averaging $70 \%$ and ranging between $25 \%$ and $89 \%$. Despite the widespread use of HSV PCR for testing of CSF, only a minority of laboratories have adopted PCR for the processing of genital swabs. This implies that approximately one third of symptomatic patients receive a false negative result, preventing appropriate counselling and often triggering additional clinic visits and investigations. The available data provide solid evidence on which to base the recommendation that PCR should replace virus culture as the diagnostic method of choice for genital herpes.

HSV typing was provided by the majority of respondents. There remains room for improvement. Differentiating between HSV types provides important prognostic information in genital herpes ${ }^{10}$ and should form an essential component of the initial assessment of all patients with newly diagnosed infection. Laboratories currently planning the adoption of PCR based assays should ensure that the protocol chosen allows for HSV typing.

HSV type specific serology has a modest diagnostic role, although its use has been increasing substantially over the last 6 years. Whereas widespread screening of asymptomatic patients for HSV type specific antibodies is not recommended, current guidelines indicate that testing can be used successfully to diagnose and manage HSV infection in certain groups. ${ }^{11}{ }^{12}$ These include people with recurrent genital symptoms of unknown aetiology, people with first episode disease including pregnant women to distinguish between newly acquired and recurrent infections, and sexual partners of people with genital herpes where there is a concern about transmission.

In recent years that have been important advances in diagnostic methods for HSV. We hope that the information presented will encourage the implementation of the new techniques, thereby increasing diagnostic accuracy and assisting with effective management.

\section{ACKNOWLEDGEMENTS}

We wish to thank the UK Clinical Virology Network for help with the distribution of the questionnaire and wish to acknowledge the contribution of the following Specialist Virology Centres and Units: Aberdeen, Belfast; Birmingham; Bristol; Cambridge; Cardiff; Dundee; Edinburgh; Glasgow; Leeds; Liverpool; London St Bartholomew's and Royal London; London Royal Free; London University College; London St George's; London St Thomas's; London King's College and Health Protection Agency; London St Mary's, Chelsea and Westminster, Charing Cross and Hammersmith; Manchester; Newcastle; Oxford; Portsmouth; Reading; Sheffield; Southampton. We also wish to acknowledge the valuable contribution of all other members of the BASHH Specialist Interest Group on Genital Herpes: Dr Simon Barton, Ms Jane Bickford, Dr Susan Drake, Dr John Green, Dr James Hickling, Dr George Kinghorn, Ms Marian Nicholson, Dr Raj Patel, and Dr Anne Scoular.

\section{CONTRIBUTORS}

$\mathrm{DB}$ and $\mathrm{AMG}$ designed the questionnaire and analysed the data; AMG wrote the first draft of the manuscript; DB reviewed the first draft of the manuscript and contributed to writing the paper in its final form; the BASHH Specialist Interest Group on Genital Herpes reviewed and approved the manuscript.

\section{Authors' affiliations}

A M Geretti, Department of Virology, Royal Free Hospital and Royal Free and University College Medical School, Pond Street, London NW3 2QG, UK

D W Brown, Enteric, Respiratory and Neurological Virus Laboratory, Specialist and Reference Microbiology Division, Health Protection Agency, 61 Colindale Avenue, London NW9 5HT, UK

Competing interest: None.

On behalf of the British Association for Sexual Health and HIV (BASHH) Specialist Interest Group on Genital Herpes, and the UK Clinical Virology Network (CVN).

\section{REFERENCES}

1 Scoular A, Kinghorn G. British Co-operative Clinical Group national survey on diagnostic issues surrounding genital herpes. MSSVD Special Interest Group on Genital Herpes and the British Co-operative Clinical Group. Sex Transm Infect 1999;75:403-5.

2 Scoular A. Using the evidence base on genital herpes: optimising the use of diagnostic tests and information provision. Sex Transm Infect 2002; 78: 160-5.

3 Ramaswamy M, McDonald C, Smith M, et al. Diagnosis of genital herpes by real-time PCR in routine clinical practice. Sex Transm Infect 2004:80:406-10.

4 Gopal R, Gibbs T, Slomka MJ, et al. A monoclonal blocking EIA for herpes simplex virus type 2 antibody: validation for seroepidemiological studies in frica. J Virol Methods 2000:87:71-80.

5 Burrows J, Nitsche A, Bayly B, et al. Detection and subtyping of Herpes simplex virus in clinical samples by LightCycler PCR, enzyme immunoassay and cell culture. BMC Microbiol 2002;2:2-12

6 Aldea C, Alvarez CP, Folgueira L, et al. Rapid detection of herpes simplex virus DNA in genital ulcers by real-time PCR using SYBR green I dye as the detection signal. J Clin Microbiol 2002;40:1060-2.

7 Van Doornum GJ, Guldemeester J, Osterhaus AD, et al. Diagnosing herpesvirus infections by real-time amplification and rapid culture. J Clin Microbiol 2003:41:576-80.

8 Wald A, Huang ML, Carrell D, et al. Polymerase chain reaction for detection of herpes simplex virus (HSV) DNA on mucosal surfaces: comparison with HSV isolation in cell culture. J Infect Dis 2003; 188:1345-51

9 Schmutzhard J, Merete RH, Zweygberg WB, et al. Detection of herpes simplex virus type 1 , herpes simplex virus type 2 and varicella-zoster virus in skin lesions. Comparison of real-time PCR, nested PCR and virus isolation. J Clin Virol 2004;29:120-6.

10 Benedetti J, Corey L, Ashley R. Recurrence rates in genital herpes after symptomatic first-episode infection. Ann Intern Med 1994;121:847-54.

11 Centers for Disease Control, Atlanta, USA. Sexually transmitted diseases treatment guidelines, 2002. (www.cdc.gov/STD/treatment/22002TG.htm \#GenitalHerpes, accessed July 2004).

12 International Herpes Management Forum. Guidelines. Diagnosis of genital HSV infection. (www.ihmf.org/guidelines/summary7.asp\#Genital HSV, accessed July 2004). 